Article

\title{
An Alternative Co-Benefit Framework Prioritizing Health Impacts: Potential Air Pollution and Climate Change Mitigation Pathways through Energy Sector Fuel Substitution in South Korea
}

\author{
Dafydd Phillips (D) and Tae Yong Jung * \\ Graduate School of International Studies, Yonsei University, Seoul 03722, Korea; dafydd.phillips@yonsei.ac.kr \\ * Correspondence: tyjung00@yonsei.ac.kr
}

\begin{abstract}
South Korea had the highest annual average PM2.5 exposure levels in the Organization for Economic Co-operation and Development (OECD) in 2019, and air pollution is consistently ranked as citizens' top environmental concern. South Korea is also one of the world's top ten emitter countries of $\mathrm{CO}_{2}$. Co-benefit mitigation policies can address both air pollution and climate change. Utilizing an alternative co-benefit approach, which views air pollution reduction as the primary goal and climate change mitigation as secondary, this research conducts a scenario analysis to forecast the health and climate benefits of fuel substitution in South Korea's electricity generation sector. Health benefits are calculated by avoided premature mortality and years of life lost (YLL) due to ischemic heart disease, stroke, chronic obstructive pulmonary disease (COPD), lung cancer, and acute lower respiratory infections (ALRI). The study finds that use of liquefied natural gas (LNG) instead of coal over the 2022-2050 period would result in an average of 116 fewer premature deaths (1152 YLL) and $80.8 \mathrm{MTCO}_{2} \mathrm{e}$ fewer emissions per year. Over the same period, maintaining and maximizing the use of its nuclear energy capacity, combined with replacing coal use with LNG, would result in an average of 161 fewer premature deaths (1608 YLL) and $123.7 \mathrm{MTCO}_{2} \mathrm{e}$ fewer emissions per year.
\end{abstract}

Keywords: air pollution; PM2.5; climate change mitigation; co-benefits; South Korea; LEAP-IBC

\section{Introduction}

Ambient (outdoor) air pollution is a serious problem that affects the health and wellbeing of people all over the world, with around 91\% of the world's population residing in areas where ambient air quality is below World Health Organization (WHO) recommended levels in 2016 [1]. PM2.5 and ground-level $\mathrm{O}_{3}$, which are associated with respiratory and cardiovascular diseases and mortality, have potentially the most significant effects on human health compared to other air pollutants [2-4]. PM2.5 is particularly detrimental to human health as these particles can be breathed deeply into the lungs and enter the bloodstream [5]. Exposure to PM2.5 increases the relative risk for ischemic heart disease, stroke, lung cancer, chronic obstructive pulmonary disease (COPD), and acute lower respiratory infections (ALRI) [6]. In 2015, exposure to PM2.5 caused 4.2 million deaths, representing $7.6 \%$ of total global deaths [2]. Reduction of PM2.5 exposure levels has major positive health impacts. Between 2000 and 2017, the annual PM2.5-related number of deaths in the EU decreased ( -4.85 per 106 inhabitants) in line with a reduction of PM2.5 levels observed at urban air quality monitoring stations [4]. In the absence of policies to reduce ambient air pollution it is projected that the number of annual deaths due to air pollution exposure will increase to 6-9 million by 2060 [7].

East Asia is a region that suffers from high levels of ambient air pollution. In 2015, 1.14 million deaths in the region were attributable to PM2.5 exposure, 27\% of the year's total global PM2.5-related mortality [2]. In 2019, South Korea had the highest annual average PM2.5 exposure levels in the OECD, and in 2012 the total number of deaths due 
to ambient air pollution was estimated to be 11,523 [8]. Figure 1 shows mean population exposure to PM2.5 in South Korea and the OECD from 2010-2019. The WHO Air Quality Guidelines for particulate matter (PM) recommend that the PM2.5 exposure levels not exceed $10 \mu \mathrm{g} / \mathrm{m}^{3}$ in the annual mean [9]. The negative impacts of PM2.5 exposure will become more severe into the future as South Korea is a rapidly aging society, with over $30 \%$ of South Korea's population forecasted to be aged 70 or older by 2050 .

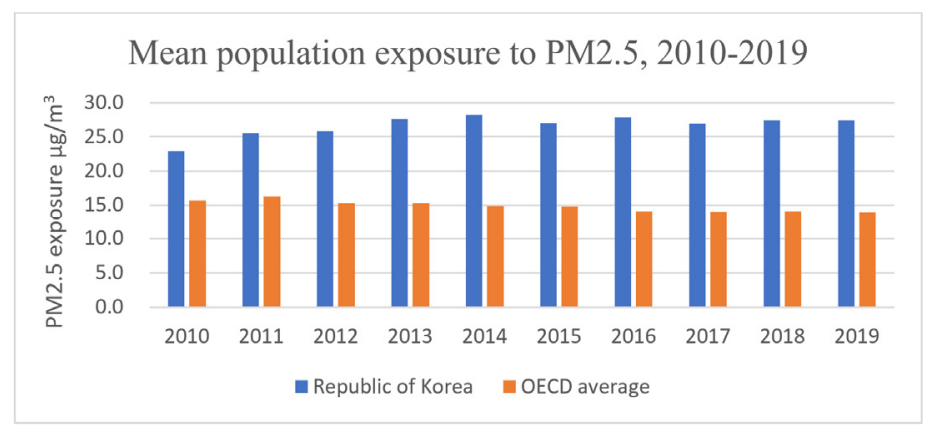

Figure 1. Mean population exposure to PM2.5 $\mu \mathrm{g} / \mathrm{m}^{3}, 2010-2019$, South Korea and the OECD average [10].

Beyond the direct health impacts of air pollution on human health, air pollution has other negative impacts such as the reduction of tourism and retail sales revenues [11], the reduction of time people spend in outdoor open spaces [12], as well as higher rates of depression associated with residing in areas with higher PM2.5 exposure [13].

Climate change is another severe environmental issue that needs to be addressed urgently. Anthropogenic emissions of greenhouse gases (GHGs) are causing severe and irrevocable damage to the global climate system, increasing the likelihood of devasting impacts for people and ecosystems [14]. South Korea is one of the world's top ten emitter countries of $\mathrm{CO}_{2}$, yet its efforts to mitigate climate change have been insufficient. Co-benefit mitigation policies can address both climate change and air pollution. Co-benefits are the extra benefits which are gained through climate change mitigation actions, beyond the direct benefits of a more stable climate [15]. However, despite the evidence of the additional benefits of climate change mitigation policies [16], implementation of mitigation measures has been slow.

This study utilizes an alternative co-benefit approach which views air pollution reduction as the primary goal and climate change mitigation as a secondary objective. There are three main reasons for taking this approach. The first is to reflect democratic will. Air pollution has been consistently found to be the top environmental concern of Korean citizens $[17,18]$. Given that air pollution is more of an immediate concern to the Korean electorate, and given that democratic government should reflect the will of the people, it is reasonable that government policy should prioritize addressing air pollution. Second, the negative impacts of air pollution are experienced after a much shorter period compared to climate change. While not to downplay the negative impacts of climate change, air pollution is causing a larger number of avoidable deaths in the near term. Even though air pollution has a large regional dimension, as in South Korea, which is strongly affected by pollutant emissions from China, national government still has the capacity to reduce premature mortality through domestic policy changes. Third, policies framed with a focus on local, immediate benefits are more likely to receive widespread support and be implemented. Policies primarily focused on issues such as climate change of which the negative impacts are not directly and rapidly experienced by the public are less likely to be supported. The result of focusing on air quality instead of climate change may lead to the outcome of greater implementation of policies which contain climate change mitigation components.

In the "9th Basic Plan for Long-term Electricity Supply and Demand (2020-2034)" [19], hereby after referred to as the "9th Basic Plan", the South Korean government outlined 
its future targets for energy mix capacities by fuel type. Renewable energy (RE) and liquefied natural gas (LNG) capacities are planned to be increased and coal and nuclear energy capacities decreased. The stated goals of the policy are to simultaneously reduce greenhouse gas (GHG) emissions and air pollution, as well as phase out nuclear energy due to safety concerns. Yet the plan still relies heavily on fossil fuel for electricity generation into the future, with $70 \%$ of total planned effective capacity being from LNG and coal in 2034, raising concerns about how South Korea will totally transform its energy mix in 15 years to meet its 2050 carbon neutrality pledge.

This research conducts a scenario analysis to forecast the health and climate benefits of further fuel substitution in South Korea's electricity generation sector, through the increased use of LNG and nuclear power compared to the 9th Basic Plan. The purpose of this research is to provide quantitative evidence for the potential benefits of alternative policy directions in South Korea's energy policy. This research focuses on LNG and nuclear generating capacities as their increased utilization can be decided by government policy relatively quickly compared to alternative energy sources such as solar and wind. South Korea is seeking to expand its use of renewable energy, but this will take time and faces barriers in the South Korean context.

Health benefits are calculated by avoided premature mortality and years of life lost (YLL) due to ischemic heart disease, stroke, COPD, lung cancer, and ALRI. The study finds that use of liquefied natural gas (LNG) instead of coal over the 2022-2050 period would result in an average of 116 fewer premature deaths (1152 YLL) and $80.8 \mathrm{MTCO}_{2} \mathrm{e}$ fewer emissions per year. Over the same period, maintaining and maximizing the use of its nuclear energy capacity, combined with replacing coal use with LNG, would result in an average of 161 fewer premature deaths (1608 YLL) and $123.7 \mathrm{MTCO}_{2} \mathrm{e}$ fewer emissions per year.

\section{Materials and Methods}

This study utilizes the Low Emissions Analysis Platform (LEAP) and its Integrated Benefits Calculator (IBC) to calculate the health and climate benefits of fuel substitution in South Korea's electricity generation sector. Developed at the Stockholm Environment Institute (SEI), LEAP is an integrated, scenario-based modeling tool that can be used to track energy consumption, production, and resource extraction in all sectors of an economy and calculate energy sector and non-energy sector GHG emission sources [20]. At least 38 countries have used LEAP to develop their National Determined Contributions (NDCs) under the Paris Agreement. The IBC approximates atmospheric concentrations of air pollutants, such as PM2.5, and then estimates the impacts on human health [21]. National emissions of relevant air pollutants and GHGs are calculated from the user-created country model based on the inputted fuel use, activity levels, and emissions factors data. Emissions from the natural background, the rest of the world, are taken from the IIASA GAINS ECLIPSE scenario [22]. LEAP-IBC translates the total emissions into populationweighted concentrations in the target country based on the GEOS-Chem adjoint model, which is a global atmospheric geochemistry model driven by meteorological inputs from NASA satellites [23]. Using integrated concentration exposure-response functions from Cohen et al. [2], which analyzed data from the 2015 Global Burden of Disease study [2], annual premature mortality and years of life lost (YLL) due PM2.5 exposure are calculated. Premature mortality is defined as the sum of deaths per year that are attributable to PM2.5 exposure which occur prior to the average life expectancy. YLL is the sum of years of life lost due to premature mortality, calculated by adding the sum of the remaining life expectancy at the age of each premature death.

The modeling framework utilized by LEAP-IBC is outlined and applied to Bangladesh in Kuylenstierna et al. [24] The study finds that full implementation of Bangladesh's NDC and National Action Plan to reduce short-lived climate pollutants (SLCPs) would result in an avoidance of 12,000 premature deaths attributable to ambient PM2.5 exposure in 2030. Nakarmi et al. [25] undertook a similar study using LEAP-IBC to examine the impacts of 
short-lived climate pollutants (SLCPs) mitigating measures on human health, agriculture, and climate in Nepal. The research found that implementation of mitigation measures could reduce PM2.5 levels by $87 \%$ by 2050 , resulting in 29,000 fewer premature deaths and avoiding 1.7 million tonnes of crop loss, leading to a present value economic benefit of 2.7 times more than the total cost incurred in its implementation period of 2010-2050. Previous studies applying LEAP to South Korea have been carried out [26-28], but there has of yet been no published study utilizing LEAP-IBC for South Korea.

The base year of this study is 2019 and the scenario years of analysis are 2022-2050. The five diseases for which premature mortality and YLL due to PM2.5 exposure are calculated for are ischemic heart disease, COPD, stroke, lung cancer, and ALRI. Premature mortality and YLL due to ALRI is estimated for the population portion under 5 years old, and, for the other four diseases, estimated for the population aged thirty years and older. The effect of PM2.5 on mortality rates is estimated through the application of the integrated exposure-response functions for each disease from Cohen et al. [2], based on analysis of data from the 2015 global burden of disease.

The integrated exposure-response functions (IERs) have the mathematical form:

$$
\operatorname{IER}(\beta, z)=1+\alpha \times\left(1-e^{-\beta\left(z-z_{c f}\right) \gamma+}\right)
$$

where $z$ is the level of PM2.5 and $z_{\mathrm{cf}}$ is the theoretical minimum risk exposure level (assigned a uniform distribution of $2.4-5.9 \mu \mathrm{g} / \mathrm{m}^{3}$ of PM2.5) below which no additional risk is assumed, with

$$
\left(\mathrm{z}-\mathrm{z}_{\mathrm{cf}}\right)_{+}=\left(\mathrm{z}-\mathrm{z}_{\mathrm{cf}}\right)
$$

if $\mathrm{z}$ is greater than $\mathrm{z}_{\mathrm{cf}}$ and zero otherwise. Here, $1+\alpha$ is the maximum risk, $\beta$ is the ratio of the IER at low to high concentrations, and $\gamma$ is the power of PM2.5 concentration.

The baseline mortality rates for each of the five diseases are a key determinant of the total PM2.5-related premature mortality and YLL of this study. The rates of mortality due to each disease for each gender by five-year age bracket for 2019 was accessed from the Korean Statistical Information Service (KOSIS) [29] and assumed to hold constant in every scenario year. A table detailing the 2019 mortality rates by disease is provided in Appendix A. Total population and population portion by five-year age bracket for the base year and baseline scenario is taken from the UN population forecast, medium fertility variant [30]. Life expectancy for each age bracket in the base year is attained from the KOSIS [31] and is projected to increase gradually to $5 \%$ by 2050 in all scenarios, in line with the UN life expectancy forecast for South Korea.

As the focus of this study is changes in the electricity generation sector, PM2.5 emissions from other domestic sectors are estimated according to a simplified framework. The purpose of including other sectors is to ensure a reasonable estimation of the total level of PM2.5 exposure in South Korea to more accurately calculate the health impacts of changes in PM2.5 emissions in the electricity generation sector. As the curve of the relative risk functions flattens at higher levels of PM2.5 exposure, it is essential to include other sectors as, without their inclusion, the positive health impacts of reduced PM2.5 emissions from South Korea's energy sector would be overestimated.

Using data from the Korea Energy Economics Institute (KEEI) [32], ton of oil equivalent (TOE) final energy consumption by fuel type for the entire South Korean economy was inputted in the base year 2019. As according to the KEEI data, fuel consumption information was divided into the following five sectors: industry, transport, residential, commercial, and public. The industrial sector includes agriculture, fishing, mining, manufacturing, and construction. Emission factors for each fuel used in the five sectors, as well as for the electricity generation sector, are inputted according to the sources used in LEAP-IBC [33-36]. For the baseline scenario the energy intensity of the industrial sector was set to decrease gradually by $21 \%$ by 2040 in accordance with South Korea's 3rd energy master plan [37]. The public, commercial, and residential sectors total energy use in the baseline scenario was projected by using the energy intensity per person of their perspective sectors in the 
base year to calculate their total energy use according to the population of each scenario year. The transport sector was calculated using the same method, and, additionally, its energy intensity was projected to gradually decrease until 2040 in accordance with the 3rd energy master plan. Emission controls were then used to reduce final emissions by the electricity generation sector and the five other sectors to bring them in line with sector emission data from the National Center for Fine Dust Information [38], and the total PM2.5 exposure level of 2019 [9].

Electricity demand is projected to follow the target demand of the 9th Basic Plan, with post-2034 electricity demand projected from the gigawatt hour (GWh) per person growth rate during the $2022-2034$ period of $0.61 \%$. Losses from transmission and distribution is set to $3.54 \%$ as according to energy statistics from the Korea Electric Power Corporation (KEPCO) [39]. An additional 4\% loss was added to the transmission and distribution module to induce the electricity generation module to produce additional GWhs to account for the fact that not all generated GWh will be consumed due to the practical realities of electricity systems. The $4 \%$ figure was derived by comparing past total GWhs generated with total GWhs demanded, minus losses due to transmission and distribution.

The electricity generation sector in the baseline follows the effective capacities of the 9th Basic Plan, outlined in Figure 2, with post-2034 effective energy capacities assumed to remain the same as the effective energy capacities of 2034. Electricity generation is divided into bituminous coal, LNG, nuclear, hydro (including pumped storage), renewable energy (RE), and miscellaneous (oil, distilled tower waste heat, residual heat recovery, natural gas pressure turbine, by-product gas). South Korea also uses some anthracite coal for electricity generation, but it accounts for only about $1 \%$ of total coal energy generation, so for this reason and the fact that the 9th Basic Plan's future year effective capacity targets do not distinguish between bituminous and anthracite coal capacity, this study assumes all electricity from coal in South Korea is produced by bituminous coal only.

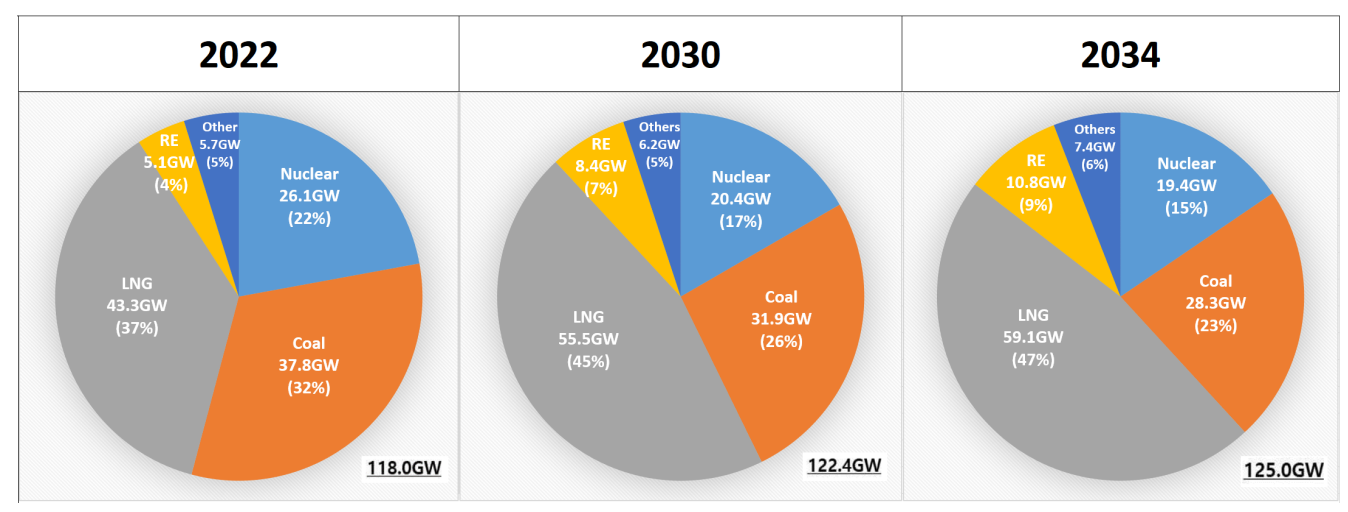

Figure 2. Planned effective capacity by year according to the 9th Basic Plan.

In the base year 2019 and previous years, coal has been used to generate disproportionally more electricity than its percentage of total effective capacity. For example, in 2019, coal generated $40 \%$ of electricity in South Korea even though it only embodied $32 \%$ of total effective capacity. Conversely, in 2019, 37\% of total effective capacity was LNG but only $26 \%$ of total electricity was generated by LNG. In both the 9th Basic Plan and the 3rd energy master plan the South Korean government has stated its intention to use more LNG and less coal to reduce air pollution and GHG emissions. To reflect this, the coal and LNG modules were dispatched proportional to their total effective capacities as outlined in the 9th Basic Plan for each scenario year. Figure 3 shows a comparison of 2019 installed capacity compared to 2019 generated electricity as a percentage of their respective totals for each fuel source. Renewable energy (RE) is dispatched according to its full projected effective capacity according to the 9th Basic Plan for each scenario year. The other energy modules were dispatched according to their average percent of effective capacity utilized during the 2016-2019 period. 
2019 installed capacity compared to generated electricity as \% of total

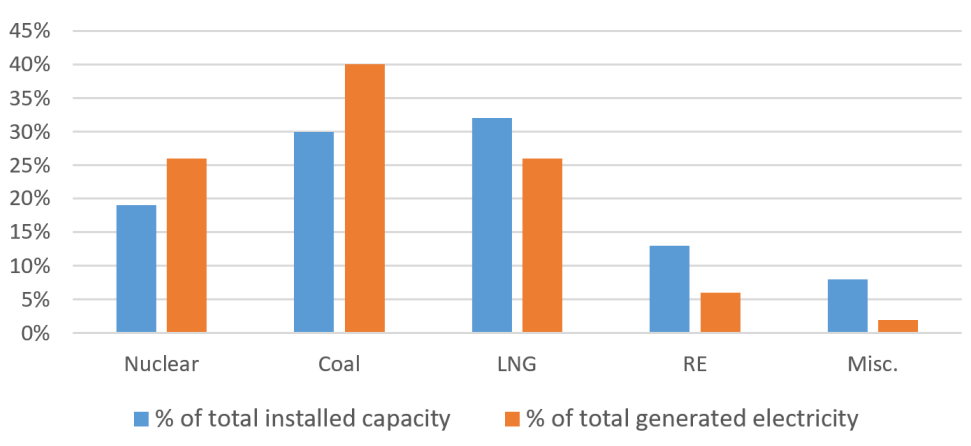

Figure 3. South Korea 2019 installed capacity compared to final energy production.

Except for stated changes in the electricity generation sector, all other values, growth rates, emission factors, etc. are the same in every scenario. Table 1 provides a description of the baseline and three alternative scenarios. It should be noted that replacing all coal electricity generation with LNG does not require the development of additional capacity beyond that outlined in the 9th Basic Plan.

Table 1. Outline of scenarios.

\begin{tabular}{cc}
\hline Scenario Name & Description \\
Baseline & $\begin{array}{c}\text { Coal and LNG dispatch in proportion to their } \\
\text { effective capacities outlined in 9th Basic Plan. } \\
\text { Renewable energy (RE) dispatches according } \\
\text { to its full effective capacity of 9th Basic Plan. } \\
\text { Nuclear, hydro, and others are dispatched } \\
\text { according to their average percent of effective } \\
\text { capacity utilized over the 2016-2019 period. }\end{array}$ \\
\hline LNG2022 & $\begin{array}{c}\text { From 2022 all coal electricity generation ceases } \\
\text { and is replaced by LNG. }\end{array}$ \\
& $\begin{array}{c}2022 \text { nuclear capacity is maintained, and its use } \\
\text { maximized. Coal and LNG dispatch } \\
\text { proportionally to their effective capacities } \\
\text { outlined in 9th Basic Plan. }\end{array}$ \\
& $\begin{array}{c}\text { 2022 nuclear capacity is maintained, and its use } \\
\text { maximized. From 2022 all coal electricity } \\
\text { generation ceases and is replaced by LNG. }\end{array}$ \\
\hline
\end{tabular}

\section{Results}

Through the created model of South Korea and the utilization of LEAP-IBC the following results were calculated. South Korea's total numbers of deaths due to PM2.5 exposure is projected to rise dramatically over the coming decades, with most premature deaths and years of life (YLL) lost being in the over-70-years age group, as shown in Figures 4 and 5 . This is due to the fact that South Korea is an aging society with rising life expectancy. 
Baseline scenario total premature deaths due to PM2.5 by year

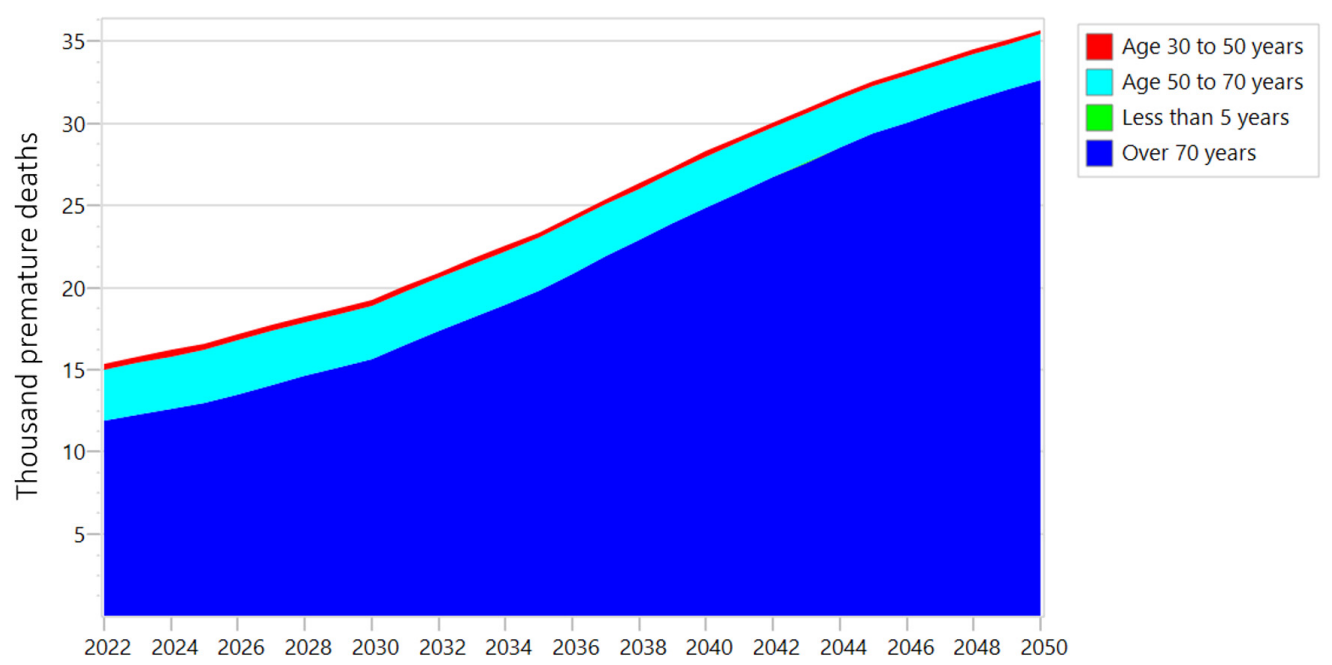

Figure 4. Projected total premature deaths by age group due to PM2.5 in baseline scenario.

Baseline scenario total years of life lost (YLL) due to PM2.5 by year

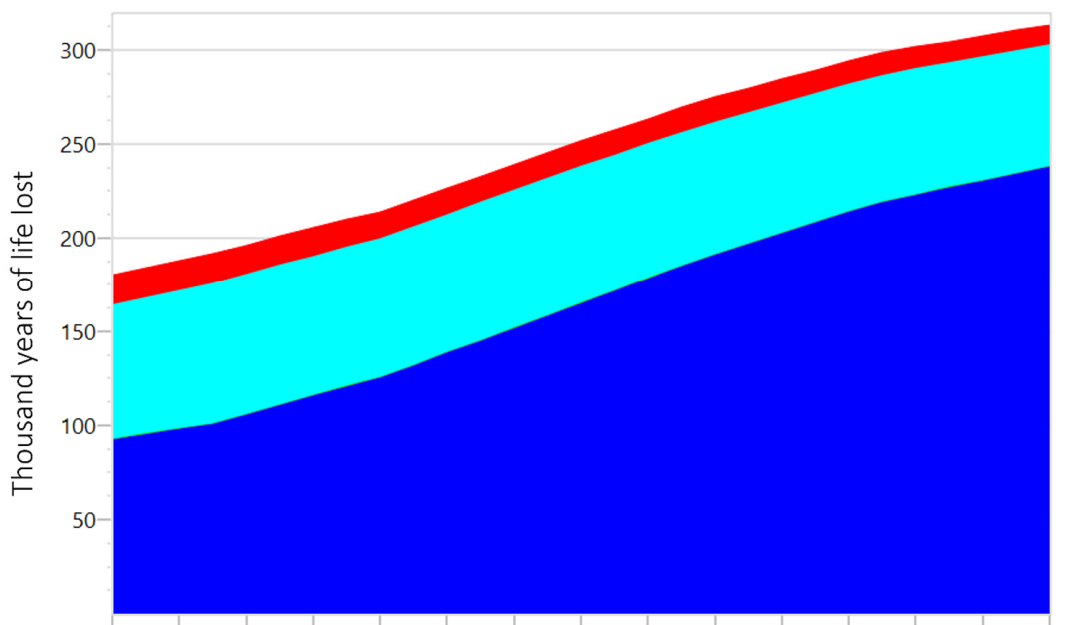

Age 30 to 50 years Age 50 to 70 years Less than 5 years Over 70 years $\begin{array}{lllllllllllllll}2022 & 2024 & 2026 & 2028 & 2030 & 2032 & 2034 & 2036 & 2038 & 2040 & 2042 & 2044 & 2046 & 2048 & 2050\end{array}$

Figure 5. Projected total years of life lost (YLL) by age group due to PM2.5 in baseline scenario.

Figure 6 shows the total gigawatt-hours (GWhs) produced by each energy source in the baseline and the three alternative scenarios.

In each of the three alternative scenarios, population exposure to PM2.5 is reduced compared to the baseline scenario, as shown in Figure 7. The "MaxNuc_LNG2022" scenario, in which 2022 nuclear capacity is maintained and its use maximized, and all remaining coal electricity generation is replaced by LNG, has the largest PM2.5 exposure reduction impact, followed by the "LNG2022" scenario and then the "MaxNuc_9thplan" scenario. 

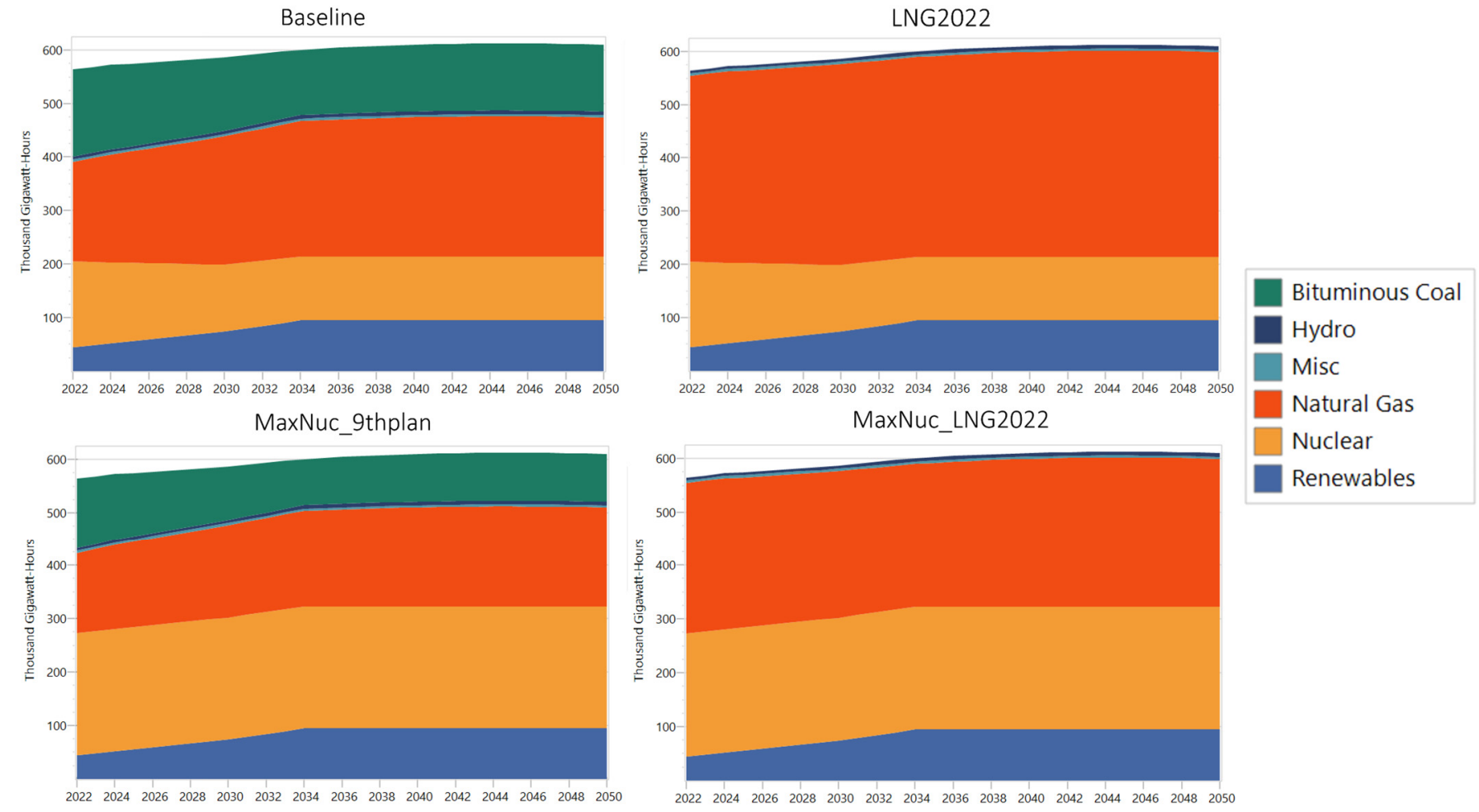

Figure 6. Gigawatt-hour (GWh) production by energy source in each scenario.
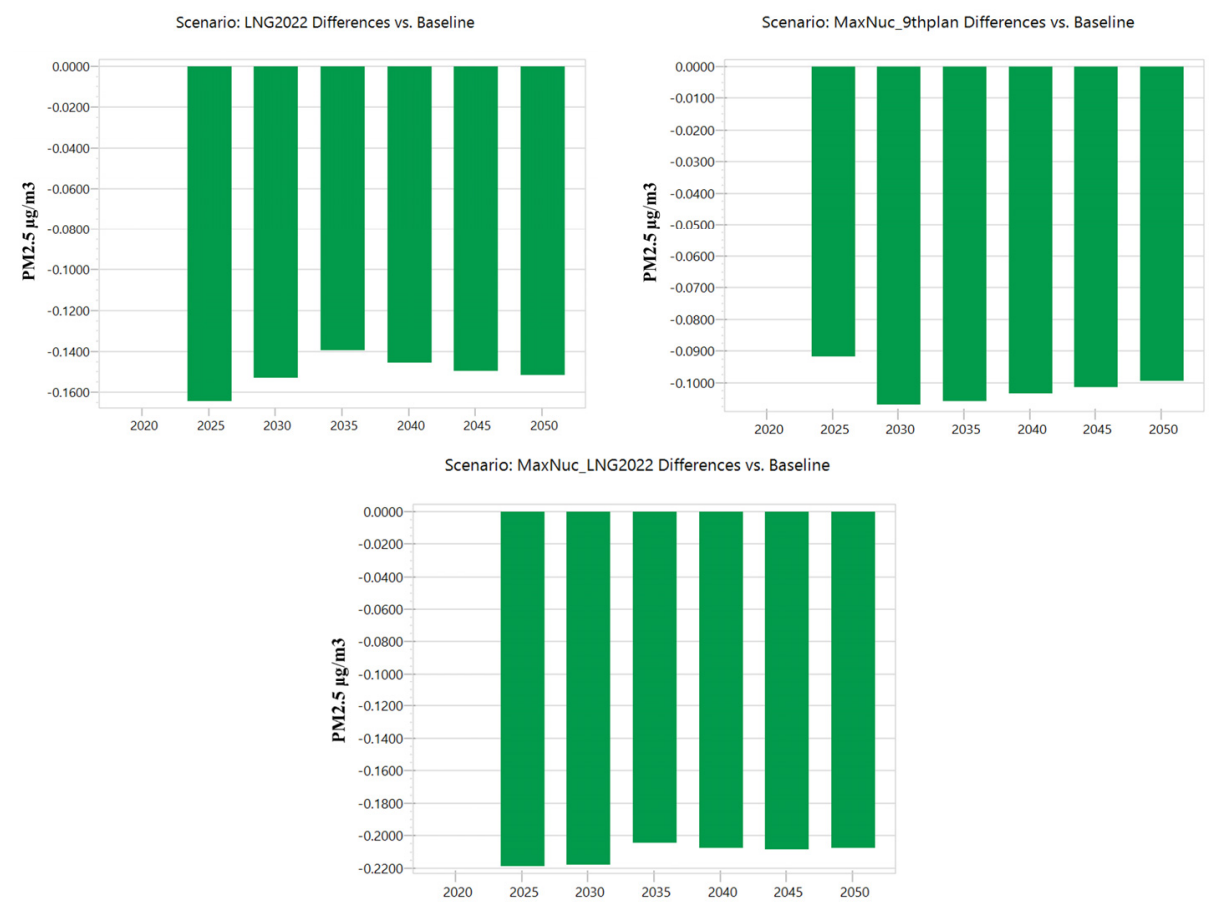

Figure 7. Reduction in population-weighted PM2.5 exposure in each alternative scenario.

The health and climate benefits of all three scenarios follow the same order in terms of positive impacts, as shown in Table 2. The "MaxNuc_LNG2022" scenario yields the largest benefits in terms of both avoided premature mortality, as shown in Figure 8, and also in terms of GHG emissions mitigation. Given the fact that nuclear power currently has the lowest cost per GWh produced in South Korea's energy system, the "MaxNuc_9thplan" scenario, in which 2022 nuclear capacity is maintained and its use maximized, would yield 
the greatest health and climate benefits relative to cost. The "LNG2022" scenario would result in the highest cost-to-benefit ratio as LNG electricity generation is more expensive than nuclear electricity generation in South Korea.

Table 2. Avoided premature mortality, years of life lost (YLL), and $\mathrm{MtCO}_{2}$ e emissions (100-year GWP) compared to baseline.

\begin{tabular}{|c|c|c|c|c|c|c|c|c|c|}
\hline \multirow[b]{2}{*}{ Year } & \multicolumn{3}{|c|}{ LNG2022 } & \multicolumn{3}{|c|}{ MaxNuc_9thplan } & \multicolumn{3}{|c|}{ MaxNuc_LNG2022 } \\
\hline & $\begin{array}{l}\text { Premature } \\
\text { Mortality }\end{array}$ & YLL & $\mathrm{MtCO}_{2} \mathrm{e}$ & $\begin{array}{l}\text { Premature } \\
\text { Mortality }\end{array}$ & YLL & $\mathrm{MtCO}_{2} \mathrm{e}$ & $\begin{array}{l}\text { Premature } \\
\text { Mortality }\end{array}$ & YLL & $\mathrm{MtCO}_{2} \mathrm{e}$ \\
\hline 2022 & 66 & 771 & 88.1 & 33 & 383 & 51.1 & 84 & 988 & 121.9 \\
\hline 2023 & 67 & 778 & 87.8 & 34 & 392 & 53.6 & 88 & 1020 & 123.3 \\
\hline 2024 & 70 & 805 & 87.4 & 37 & 426 & 56.0 & 91 & 1058 & 124.6 \\
\hline 2025 & 87 & 995 & 86.2 & 44 & 508 & 58.3 & 117 & 1350 & 125.0 \\
\hline 2026 & 76 & 872 & 85.1 & 45 & 510 & 60.5 & 103 & 1182 & 125.6 \\
\hline 2027 & 82 & 928 & 84.1 & 51 & 573 & 62.7 & 115 & 1301 & 126.1 \\
\hline 2028 & 100 & 1122 & 82.9 & 65 & 730 & 64.7 & 134 & 1498 & 126.5 \\
\hline 2029 & 94 & 1049 & 81.7 & 64 & 716 & 66.7 & 131 & 1455 & 126.8 \\
\hline 2030 & 88 & 974 & 80.7 & 61 & 674 & 68.6 & 128 & 1414 & 127.2 \\
\hline 2031 & 89 & 977 & 78.9 & 63 & 690 & 68.7 & 130 & 1424 & 125.6 \\
\hline 2032 & 91 & 978 & 77.1 & 65 & 705 & 68.7 & 132 & 1431 & 124.0 \\
\hline 2033 & 92 & 978 & 75.4 & 67 & 719 & 68.7 & 135 & 1445 & 122.4 \\
\hline 2034 & 92 & 975 & 73.5 & 70 & 736 & 68.6 & 138 & 1456 & 120.6 \\
\hline 2035 & 96 & 1008 & 74.5 & 72 & 754 & 68.3 & 143 & 1500 & 121.1 \\
\hline 2036 & 101 & 1041 & 75.4 & 76 & 782 & 67.9 & 150 & 1545 & 121.6 \\
\hline 2037 & 107 & 1082 & 76.3 & 80 & 812 & 67.6 & 157 & 1590 & 122.0 \\
\hline 2038 & 113 & 1129 & 77.1 & 84 & 839 & 67.3 & 164 & 1635 & 122.3 \\
\hline 2039 & 120 & 1180 & 77.9 & 88 & 862 & 67.0 & 170 & 1674 & 122.6 \\
\hline 2040 & 127 & 1229 & 78.6 & 91 & 885 & 66.7 & 177 & 1712 & 122.9 \\
\hline 2041 & 133 & 1272 & 79.3 & 94 & 901 & 66.4 & 185 & 1766 & 123.2 \\
\hline 2042 & 141 & 1328 & 79.9 & 98 & 930 & 66.1 & 195 & 1844 & 123.4 \\
\hline 2043 & 148 & 1381 & 80.5 & 103 & 963 & 65.8 & 205 & 1914 & 123.5 \\
\hline 2044 & 153 & 1413 & 81.0 & 106 & 980 & 65.5 & 212 & 1958 & 123.6 \\
\hline 2045 & 156 & 1424 & 81.5 & 105 & 955 & 65.3 & 216 & 1973 & 123.7 \\
\hline 2046 & 158 & 1434 & 81.9 & 103 & 936 & 65.0 & 220 & 1993 & 123.8 \\
\hline 2047 & 164 & 1467 & 82.3 & 110 & 987 & 64.7 & 229 & 2054 & 123.7 \\
\hline 2048 & 171 & 1522 & 82.6 & 119 & 1053 & 64.5 & 236 & 2093 & 123.7 \\
\hline 2049 & 183 & 1610 & 82.9 & 124 & 1091 & 64.2 & 242 & 2135 & 123.6 \\
\hline 2050 & 192 & 1674 & 83.1 & 126 & 1103 & 64.0 & 255 & 2223 & 123.4 \\
\hline
\end{tabular}

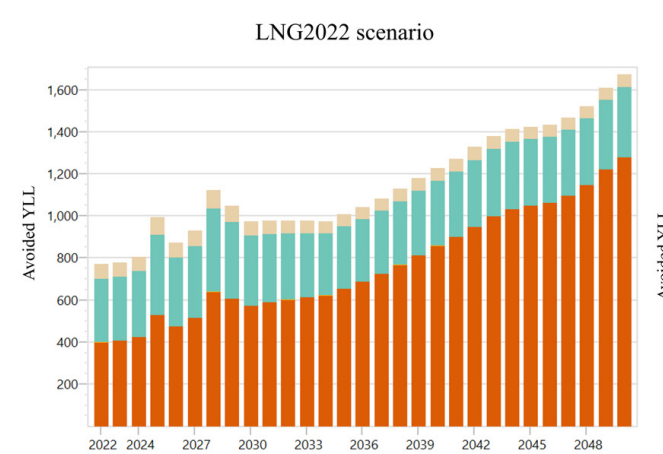

MaxNuc_LNG2022 scenario

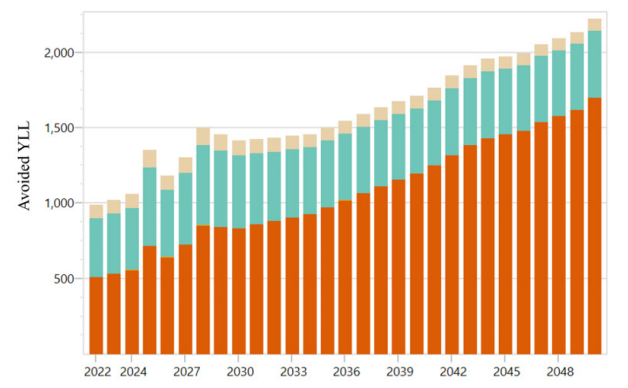

Figure 8. Avoided YLL for each scenario compared to baseline by year.
MaxNuc_9thplan scenario

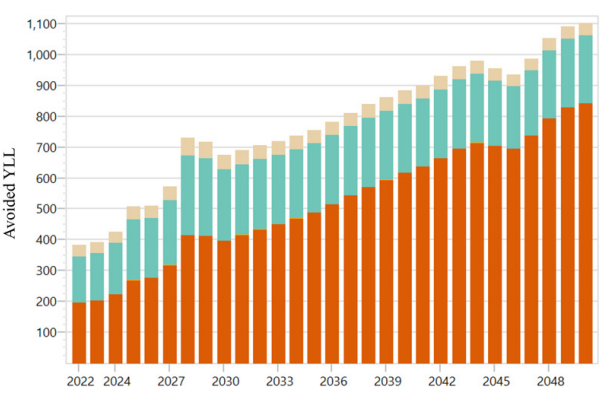

Age 30 to 50 years

Age 50 to 70 years

Less than 5 years

Over 70 years 
All three alternative scenarios would have substantial climate change mitigation impacts, with large GHG emissions mitigation in each scenario as shown in Table 2 and Figure 9. The maintenance and maximization of use of South Korea's 2022 nuclear electricity generation capacity shows strong potential to vastly reduce GHG emissions at low relative cost as nuclear electricity generation has the lowest cost per GWh generated in South Korea's energy mix and due to the fact that nuclear power generation does not directly produce any GHG emissions.

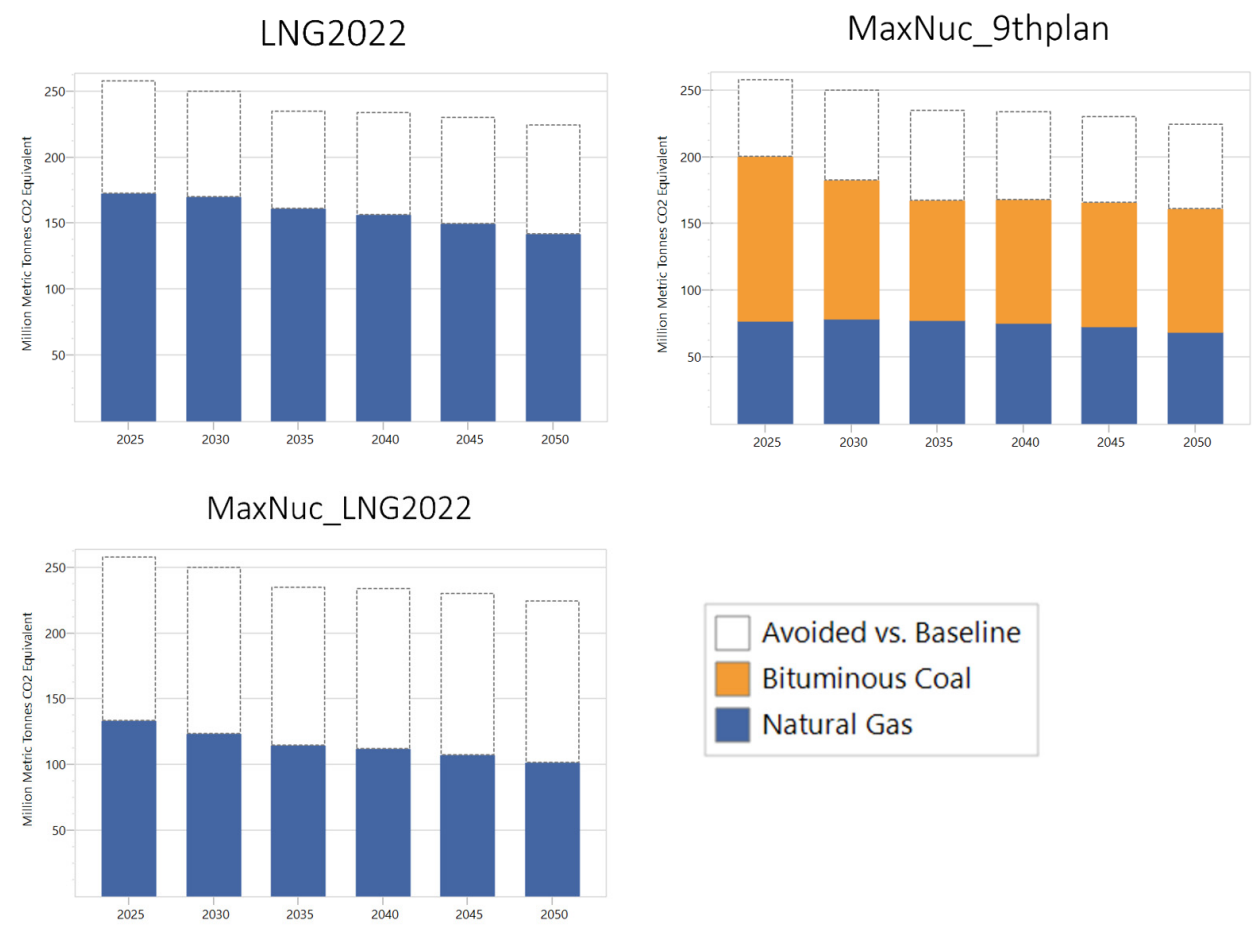

Figure 9. Energy sector million tons of $\mathrm{CO}_{2}$ equivalent $\left(\mathrm{MTCO}_{2} \mathrm{e}\right)$ emissions, and avoided emissions compared to baseline.

It should be noted that there is greater uncertainty regarding potential benefits for the post-2034 period. There is no detailed government policy outlining the planned energy mix post-2034; therefore, the baseline scenario of this research assumes that the 2034 effective energy capacities will be maintained for the 2035-2050 period. The reason this study includes analysis of 2035-2050, despite the lack of detailed government plans of effective capacities, is that as South Korea has recently announced its 2050 Carbon Neutrality goal it is important to estimate potential benefits of reduced coal use until that year. In Tables 3 and 4 the benefits are divided into the 2022-2034 and 2035-2050 periods for comparison. In the 2022-2034 period, where potential benefits can be contrasted with the detailed 9th Basic Plan, benefits are smaller than the 2035-2050 period but still significant.

Table 3. Summary of avoided premature mortality (and YLL) compared to baseline.

\begin{tabular}{ccccc}
\hline & 2022-2034 & 2035-2050 & Total & Average per Year \\
\hline LNG2022 & $1093(12,203)$ & $2263(21,193)$ & $3356(33,396)$ & $116(1152)$ \\
\hline MaxNuc_9thplan & $698(7762)$ & $1581(14,831)$ & $2278(22,593)$ & $79(779)$ \\
\hline MaxNuc_LNG2022 & $1527(17,022)$ & $3156(29,609)$ & $4683(46,631)$ & $161(1608)$ \\
\hline
\end{tabular}


Table 4. Summary of avoided $\mathrm{MTCO}_{2}$ e GHG emissions compared to baseline.

\begin{tabular}{ccccc}
\hline & $\mathbf{2 0 2 2 - 2 0 3 4}$ & $\mathbf{2 0 3 5 - 2 0 5 0}$ & Total & Average per Year \\
\hline LNG2022 & 1069 & 1275 & 2344 & 80.8 \\
\hline MaxNuc_9thplan & 817 & 1056 & 1873 & 65 \\
\hline MaxNuc_LNG2022 & 1619 & 1968 & 3588 & 123.7 \\
\hline
\end{tabular}

\section{Discussion and Conclusions}

Fuel substitution in South Korea's electricity generation sector would help mitigate national PM2.5 levels and thus reduce PM2.5-related premature mortality. As South Korea is an aging society, the negative effects of high PM2.5 exposure levels will become more severe in the future, and increased use of LNG and nuclear power would lead to significant health benefits. Additionally, the increased use of LNG and nuclear would move South Korea towards a Paris Agreement-compatible low carbon development pathway.

The study finds that use of LNG instead of coal over the 2022-2050 period would result in an average of 116 fewer premature deaths (1152 YLL) and $80.8 \mathrm{MTCO}_{2} \mathrm{e}$ fewer emissions per year in South Korea. Over the same period, maintaining and maximizing use of its 2022 nuclear energy capacity, combined with replacing coal use with LNG, would result in an average of 161 fewer premature deaths (1608 YLL) and $123.7 \mathrm{MTCO}_{2} \mathrm{e}$ fewer emissions per year. Maintaining and maximizing its 2022 nuclear electricity generation capacity would lead to the greatest avoidance of premature mortality and GHG emissions relative to cost. Given the benefits of maximizing the use of nuclear power, and given that nuclear power is the cheapest available large-scale electricity option in the near term, the South Korean government should carefully consider its current plan to phase out nuclear energy and communicate the costs and benefits of using nuclear power clearly to the public.

However, the limitations to larger-scale use of LNG and nuclear in the context of South Korea must be acknowledged. South Korea does not have a domestic supply of natural gas or access to gas pipelines; therefore, it must rely on expensive LNG imports. The cost and price uncertainty of importing LNG as a fuel source for power generation is a significant impediment to increased use of LNG. For example, in early 2021, due to a colder winter in Northeast Asia increasing LNG demand, as well as production problems in Malaysia, spot market value of LNG cargoes reached a record high. To address this issue, South Korea is expanding its LNG storage capacities to avoid having to purchase LNG on the international market at periods of high prices, but LNG will likely remain expensive relative to other fuel options into the future. Nuclear power is currently the cheapest electricity generation option available to South Korea, but public opposition to nuclear power has intensified since the 2011 Fukushima nuclear disaster. Public concern will need to be addressed first before increasing the use of nuclear power.

Increased use of renewable energy (RE) instead of coal would yield similar health and climate benefits as nuclear power, but there are significant barriers to the expansion of renewable energy generating capacity in South Korea. Practical limitations are the lack of constant wind for wind power generation and lack of space for large solar PV sites [40]. The lack of effective support for small-scale RE providers and local opposition to RE sites construction are major issues as well. In 2016, 37.5\% of canceled or postponed solar PV and wind power projects in South Korea were the result of local opposition [41]. Profit sharing has been suggested as a means of reducing local opposition, but this may be insufficient in isolation. Given the health and climate benefits of renewable energy, its use should be expanded as much and as rapidly as is possible.

The framing of a policy can have a substantial impact on its chances of being implemented. The alternative co-benefit framework outlined in this research focuses on air pollution as the primary goal, and climate change as a secondary goal. Focusing on local benefits, such as reduced air pollution, can lead to greater support for policy action and tolerance for high initial costs. Climate action is currently not a high-ranking concern of the South Korean electorate. Therefore, stressing the local and near-term positive outcomes 
of climate change mitigation action would be a potential means of improving support policies containing climate change mitigation effects. Through the increased use of LNG and nuclear energy, as well as development of renewable energy, both air pollution and climate change mitigation can be achieved.

The limitations of this study are the long-term uncertainty of total PM2.5 emissions outside of South Korea's energy sector and the fact this study assumes that baseline mortality rates by age bracket for each disease will remain constant throughout the 2022-2050 period. As South Korea's energy sector is only responsible for a portion of South Korea's total PM2.5 exposure levels, the scale of the health benefits of using alternative fuels to coal will be significantly affected by the changes in PM2.5 emissions from both other domestic sectors and other countries in the region. Baseline mortality rates for each disease could rise or fall in the future, which would also affect the amount of premature mortality and YLL in projections. The certainty of the results of this study could be improved by more detailed accounting and estimation of future domestic and international PM2.5 emissions outside of South Korea's energy sector. Utilizing a concrete government plan with details of South Korea's planned post-2034 energy capacities for comparison would also enable a more accurate calculation of the benefits of alternative energy pathways.

The lack of predictability and consistency between different administrations' energy policies is a major issue that needs to be addressed in South Korea. Long-term policy directions often change with each new administration. For example, in 2014 under the conservative Park Geun-hye administration the 2nd energy master plan was announced, which outlined policies until 2035 and included as a key point the goal to maximize the use of nuclear energy in the energy mix, due to its economic and environmental benefits [42]. However, in 2019 under the liberal Moon Jae-in administration the 3rd energy master plan was released, which announced the goal to phase out nuclear energy entirely from South Korea's energy mix [37]. The lack of long-term commitment to a clear policy direction in its energy sector will likely be a hindrance to South Korea's goal of achieving carbon neutrality by 2050 .

As pollution knows no political boundaries, mitigation of air pollution and its negative impacts requires urgent action to be taken at all governance levels. While this study focuses on national energy sector policy options to reduce PM2.5 levels in South Korea, South Korea is strongly affected by air pollutants emitted from neighboring countries, particularly China [43-46]. Therefore, long-term regional cooperation and the reduction of air pollutant emissions is essential for a more impactful reduction of PM2.5 levels and PM2.5-related premature mortality in South Korea.

Author Contributions: Conceptualization, D.P. and T.Y.J.; methodology, D.P.; software, D.P.; validation, D.P.; formal analysis, D.P.; investigation, D.P.; resources, D.P.; data curation, D.P.; writingoriginal draft preparation, D.P.; writing - review and editing, D.P. and T.Y.J.; visualization, D.P.; supervision, T.Y.J.; project administration, T.Y.J. All authors have read and agreed to the published version of the manuscript.

Funding: This research received no external funding.

Institutional Review Board Statement: Not applicable.

Informed Consent Statement: Not applicable.

Data Availability Statement: Publicly available datasets (UN Population Prospects 2019, KOSIS Death Rates by Cause for South Korea 2019, and KEEI Monthly Energy Statistics 2020/12 were used for scenario development in this study. The data can be found here: https://population.un.org/ wpp/Publications/ (accessed on 4 October 2020), https://kosis.kr/eng/ (accessed on 25 December 2020) and http:/ / www.kesis.net/ (accessed on 11 February 2021) respectively.

Acknowledgments: This research was supported by Charlie Heaps and the rest of the LEAP development team of the Stockholm Environment Institute (SEI) through their development and provision of the Low Emissions Analysis Platform (LEAP) - Integrated Benefits Calculator (IBC).

Conflicts of Interest: The authors declare no conflict of interest. 


\section{Appendix A}

Table A1. 2019 deaths per 100,000 people by gender in each age bracket due to ischemic heart disease, stroke, chronic obstructive pulmonary disease (COPD), and lung cancer in South Korea.

\begin{tabular}{|c|c|c|c|c|c|c|c|c|}
\hline & $\begin{array}{l}\text { Ischemic Heart } \\
\text { Disease, Male }\end{array}$ & $\begin{array}{l}\text { Ischemic Heart } \\
\text { Disease, Female }\end{array}$ & $\begin{array}{c}\text { Stroke, } \\
\text { Male }\end{array}$ & $\begin{array}{l}\text { Stroke, } \\
\text { Female }\end{array}$ & $\begin{array}{l}\text { COPD, } \\
\text { Male }\end{array}$ & $\begin{array}{l}\text { COPD, } \\
\text { Female }\end{array}$ & $\begin{array}{c}\text { Lung Cancer, } \\
\text { Male }\end{array}$ & $\begin{array}{c}\text { Lung Cancer, } \\
\text { Female }\end{array}$ \\
\hline 30-34 years old & 2.3 & 0.2 & 1.8 & 1.6 & 0.2 & 0.1 & 0.2 & 0.3 \\
\hline 35-39 years old & 4.1 & 0.5 & 4.5 & 2.5 & 0.2 & 0.1 & 1.0 & 0.6 \\
\hline 40-44 years old & 6.4 & 0.9 & 8.2 & 4.3 & 0.2 & 0.1 & 3.2 & 2.3 \\
\hline 45-49 years old & 12.6 & 1.7 & 12.8 & 6.9 & 0.4 & 0.3 & 6.6 & 4.0 \\
\hline 50-54 years old & 21.9 & 2.3 & 22.0 & 9.6 & 1.4 & 0.6 & 13.0 & 7.3 \\
\hline 55-59 years old & 28.3 & 4.1 & 31.1 & 13.1 & 3.5 & 0.6 & 34.5 & 11.8 \\
\hline 60-64 years old & 42.8 & 8.3 & 45.0 & 17.9 & 8.0 & 2.1 & 75.1 & 22.2 \\
\hline 65-69 years old & 62.4 & 15.7 & 75.9 & 33.3 & 21.5 & 4.0 & 157.8 & 34.6 \\
\hline $70-74$ years old & 98.8 & 34.0 & 128.9 & 65.2 & 45.9 & 10.3 & 264.1 & 55.4 \\
\hline $75-79$ years old & 174.9 & 96.4 & 294.9 & 166.5 & 123.4 & 23.0 & 446.7 & 89.3 \\
\hline 80 years or older & 437.3 & 352.2 & 702.8 & 603.7 & 397.8 & 140.8 & 674.1 & 174.8 \\
\hline
\end{tabular}

\section{References}

1. World Health Organisation (WHO). Ambient Air Pollution. Available online: https://www.who.int/teams/environmentclimate-change-and-health/air-quality-and-health/ambient-air-pollution (accessed on 3 January 2021).

2. Cohen, A.J.; Brauer, M.; Burnett, R.; Anderson, H.R.; Frostad, J.; Estep, K.; Balakrishnan, K.; Brunekreef, B.; Dandona, L.; Dandona, R.; et al. Estimates and 25-Year Trends of the Global Burden of Disease Attributable to Ambient Air Pollution: An Analysis of Data from the Global Burden of Diseases Study 2015. Lancet 2017, 389, 1907-1918. [CrossRef]

3. European Environmental Agency (EEA). Air Quality in Europe-2018 Report No. 12/2018; European Environmental Agency (EEA): Copenhagen, Denmark, 2018. [CrossRef]

4. Sicard, P.; Agathokleous, E.; De Marco, A.; Paoletti, E.; Calatayud, V. Urban Population Exposure to Air Pollution in Europe over the Last Decades. Environ. Sci. Eur. 2021, 33, 28. [CrossRef] [PubMed]

5. Environmental Protection Agency (EPA). Particulate Matter (PM) Basics. Available online: https://www.epa.gov/pm-pollution/ particulate-matter-pm-basics (accessed on 14 January 2021).

6. Burnett, R.T.; Pope, C.A.; Ezzati, M.; Olives, C.; Lim, S.S.; Mehta, S.; Shin, H.H.; Singh, G.; Hubbell, B.; Brauer, M.; et al. An Integrated Risk Function for Estimating the Global Burden of Disease Attributable to Ambient Fine Particulate Matter Exposure. Environ. Health Perspect. 2014, 122, 397-403. [CrossRef] [PubMed]

7. OECD. The Economic Consequences of Outdoor Air Pollution; OECD: Paris, France, 2016; Available online: www.oecd.org/ environment/the-economic-consequences-of-outdoor-air-pollution-\%0A9789264257474-en.htm (accessed on 8 December 2020).

8. WHO. Ambient Air Pollution: A Global Assessment of Exposure and Burden of Disease; World Health Organization: Geneva, Switzerland, 2016.

9. WHO. WHO Air Quality Guidelines for Particulate Matter, Ozone, Nitrogen Dioxide and Sulfur Dioxide; World Health Organization: Geneva, Switzerland, 2005.

10. OECD. Air Quality and Health: Exposure to PM2.5 Fine Particles-Countries and Regions; OECD Environment Statistics: Paris, France, 2020. [CrossRef]

11. Yoon, H. Effects of Particulate Matter $\left(\mathrm{PM}_{10}\right)$ on Tourism Sales Revenue: A Generalized Additive Modeling Approach. Tour. Manag. 2019, 74, 358-369. [CrossRef]

12. Choi, Y.; Yoon, H.; Kim, D. Where Do People Spend Their Leisure Time on Dusty Days? Application of Spatiotemporal Behavioral Responses to Particulate Matter Pollution. Ann. Reg. Sci. 2019, 63, 317-339. [CrossRef]

13. Jeon, H.S.; Lee, S.; Lee, J.; Chun, J.S. Impacts of Multilevel Factors on Depressive Symptoms among Adolescents in South Korea. Child. Youth Serv. Rev. 2020, 119, 105591. [CrossRef]

14. Intergovernmental Panel on Climate Change (IPCC). Climate Change 2014: Synthesis Report. Contribution of Working Groups I, II and III to the Fifth Assessment Report of the Intergovernmental Panel on Climate; IPCC: Geneva, Switzerland, 2014; Available online: https:/ / www.ipcc.ch/report/ar5/syr/ (accessed on 24 February 2021).

15. OECD. Ancillary Benefits and Costs of Greenhouse Gas Mitigation; OECD: Paris, France, 2000. [CrossRef]

16. Parry, I.; Veung, C.; Heine, D. How Much Carbon Pricing Is in Countries' Own Interests? The Critical Role of Co-Benefits. Clim. Chang. Econ. 2015, 6, 1550019. [CrossRef]

17. Air Pollution No. 1 Environmental Concern for Koreans: Survey; The Korea Times: Seoul, Korea, 2020; Available online: https: / / www.koreatimes.co.kr/www / nation/2020/07/371_292668.html (accessed on 4 September 2020).

18. Polled Citizens, Experts Prioritize Fine Dust in Environmental Policies; The Korea Times: Seoul, Korea, 2020; Available online: https:/ / www.koreatimes.co.kr/www/nation/2020/06/371_291148.html (accessed on 4 September 2020). 
19. Ministry of Trade Industry and Energy Republic of Korea. The 9th Basic Plan for Long-Term Electricity Supply and Demand; Ministry of Trade Industry and Energy Republic of Korea: Sejong, Korea, 2020. Available online: http://www.motie.go.kr/motie/ne/ presse/press2/bbs/bbsView.do?bbs_seq_n=163670\&bbs_cd_n=81 (accessed on 25 January 2021).

20. LEAP Introduction. Available online: https:/ / leap.sei.org/default.asp?action=introduction (accessed on 9 October 2020).

21. Stockholm Environment Institute (SEI). The Long-Range Energy Alternatives Planning-Integrated Benefits Calculator (LEAP-IBC) Key Features in LEAP-IBC; Stockholm Environment Institute: Stockholm, Sweden, 2017; Available online: https:/ / mediamanager.sei. org/documents/Publications/SEI-Factsheet-LEAP-IBC-2.pdf (accessed on 21 September 2020).

22. IIASA ECLIPSE V5a Global Emission Fields. Available online: https://iiasa.ac.at/web/home/research/researchPrograms/air/ ECLIPSEv5a.html (accessed on 17 February 2021).

23. Henze, D.K.; Hakami, A.; Seinfeld, J.H. Development of the Adjoint of GEOS-Chem. Atmos. Chem. Phys. 2007, 7, 2413-2433. [CrossRef]

24. Kuylenstierna, J.C.I.; Heaps, C.G.; Ahmed, T.; Vallack, H.W.; Hicks, W.K.; Ashmore, M.R.; Malley, C.S.; Wang, G.; Lefevre, E.N.; Anenberg, S.C.; et al. Development of the Low Emissions Analysis Platform-Integrated Benefits Calculator (LEAP-IBC) Tool to Assess Air Quality and Climate Co-Benefits: Application for Bangladesh. Environ. Int. 2020, 145, 106155. [CrossRef] [PubMed]

25. Nakarmi, A.M.; Sharma, B.; Rajbhandari, U.S.; Prajapati, A.; Malley, C.S.; Kuylenstierna, J.C.I.; Vallack, H.W.; Henze, D.K.; Panday, A. Mitigating the Impacts of Air Pollutants in Nepal and Climate Co-Benefits: A Scenario-Based Approach. Air Qual. Atmos. Health 2020, 13, 361-370. [CrossRef]

26. Park, N.B.; Yun, S.J.; Jeon, E.C. An Analysis of Long-Term Scenarios for the Transition to Renewable Energy in the Korean Electricity Sector. Energy Policy 2013, 52, 288-296. [CrossRef]

27. Hong, J.H.; Kim, J.; Son, W.; Shin, H.; Kim, N.; Lee, W.K.; Kim, J. Long-Term Energy Strategy Scenarios for South Korea: Transition to a Sustainable Energy System. Energy Policy 2019, 127, 425-437. [CrossRef]

28. Lee, S.; Park, J.W.; Song, H.J.; Maken, S.; Filburn, T. Implication of $\mathrm{CO}_{2}$ Capture Technologies Options in Electricity Generation in Korea. Energy Policy 2008, 36, 326-334. [CrossRef]

29. Korean Statistical Information Service (KOSIS). Deaths and Death Rates by Cause (236 Item), Sex, and Age (by Five-Year Age Group); Korean Statistical Information Service (KOSIS): Daejeon, Korea, 2020; Available online: https:/ / kosis.kr/eng/ (accessed on 25 December 2020).

30. United Nations Department of Economic and Social Affairs. World Population Prospect 2019: Population by Age Groups—Both Sexes 2019; United Nations: New York, NY, USA, 2019.

31. Korean Statistical Information Service (KOSIS). Complete Life Tables; Korean Statistical Information Service (KOSIS): Daejeon, Korea, 2020; Available online: https:// kosis.kr/statHtml/statHtml.do?orgId=101\&tblId=DT_1B42 (accessed on 10 November 2020).

32. Korean Energy Economics Institute (KEEI). Monthly Energy Statistics 2020/12; Korean Energy Economics Institute: Ulsan, Korea, 2020; Available online: http:/ / www.kesis.net/sub/sub_0003.jsp (accessed on 11 February 2021).

33. IPCC. IPCC Guidelines for National Greenhouse Gas Inventories Stationary Combustion; IPCC: Geneva, Switzerland, 2006; Volume 2. [CrossRef]

34. EEA; Berdowski, J.J.M.; Verhoeve, P. EEA Combustion in Energy and Transformation Industries; European Environment Agency: Copenhagen, Denmark, 2016; pp. 1-124.

35. Bond, T.C.; Streets, D.G.; Yarber, K.F.; Nelson, S.M.; Woo, J.H.; Klimont, Z. A Technology-Based Global Inventory of Black and Organic Carbon Emissions from Combustion. J. Geophys. Res. Atmos. 2004, 109, 1-43. [CrossRef]

36. Battye, R.; Battye, W.; Overcash, C.; Fudge, S. Development and Selection of Ammonia Emission Factors. In EPA Contract 68-D3 0034; EPA: Research Triangle Park, NC, USA, 1994; pp. 1-111.

37. Ministry of Trade, industry and Energy (MOTIE). Third Energy Master Plan; Ministry of Trade, Industry and Energy: Sejong, Korea, 2019.

38. National Center for Fine Dust Information, Emissions by Sector. Available online: https: / / airemiss.nier.go.kr (accessed on 26 December 2020).

39. Korea Electric Power Corporation KEPCO. 2020 KEPCO in Brief; Korea Electric Power Corporation: Naju, Korea, 2020; Available online: https://home.kepco.co.kr/kepco/KO/ntcob/list.do?boardCd=BRD_000098\&menuCd=FN05030102 (accessed on 13 March 2021).

40. Jung, T.Y.; Park, C. Estimation of the Cost of Greenhouse Gas Reduction in Korea under the Global Scenario of $1.5^{\circ} \mathrm{C}$ Temperature Increase. Carbon Manag. 2018, 9, 503-513. [CrossRef]

41. Kim, K.J.; Lee, H.; Koo, Y. Research on Local Acceptance Cost of Renewable Energy in South Korea: A Case Study of Photovoltaic and Wind Power Projects. Energy Policy 2020, 144, 111684. [CrossRef]

42. Ministry of Trade, Industry and Energy (MOTIE). Second Energy Master Plan; Ministry of Trade, Industry and Energy: Sejong, Korea, 2014.

43. Kim, Y.; Kim, S.W.; Yoon, S.C.; Kim, M.H.; Park, K.H. Aerosol Properties and Associated Regional Meteorology during Winter Pollution Event at Gosan Climate Observatory, Korea. Atmos. Environ. 2013, 85, 9-17. [CrossRef]

44. Lee, S.; Ho, C.H.; Choi, Y.S. High-PM10 Concentration Episodes in Seoul, Korea: Background Sources and Related Meteorological Conditions. Atmos. Environ. 2011, 45, 7240-7247. [CrossRef]

45. Lee, S.; Ho, C.H.; Lee, Y.G.; Choi, H.J.; Song, C.K. Influence of Transboundary Air Pollutants from China on the High-PM10 Episode in Seoul, Korea for the Period October 16-20, 2008. Atmos. Environ. 2013, 77, 430-439. [CrossRef]

46. Lee, H.; Park, S.S.; Kim, K.W.; Kim, Y.J. Source Identification of PM2.5 Particles Measured in Gwangju, Korea. Atmos. Res. 2008, 88, 199-211. [CrossRef] 